DOI: http://dx.doi.org/10.33846/hn40604

http://heanoti.com/index.php/hn

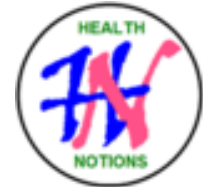

RESEARCH ARTICLE

URL of this article: http://heanoti.com/index.php/hn/article/view/hn40604

\title{
Comparison of Sarcopenia Diagnostic Component Between Two Age Groups in Men
}

Yahya Taqiuddin Robbani ${ }^{1(\mathrm{CA})}$, Novira Widajanti ${ }^{2}$, Nuniek Nugraheni Sulistiawaty ${ }^{3}$

${ }^{1(\mathrm{CA})}$ Medicine Program, Faculty of Medicine, Universitas Airlangga, Indonesia; yahya.taqiuddin.robbani@gmail.com (Corresponding Author)

${ }^{2}$ Department of Internal Medicine, Faculty of Medicine, Universitas Airlangga / Dr. Soetomo General Hospital Surabaya, Indonesia; novirawidajanti@fk.unair.ac.id

${ }^{3}$ Department of Physical and Rehabilitation Medicine, Faculty of Medicine, Universitas Airlangga, Dr. Soetomo General Hospital Surabaya, Indonesia; nuniek.nugraheni@fk.unair.ac.id

\begin{abstract}
Sarcopenia is a condition which characterized by loss of muscle mass, muscle strength and muscle function due to aging. Some study found that sarcopenia prevalence was more common in men than women. This study aims to determine the comparison of sarcopenia diagnostic component between two group ages in men by observing and comparing muscle mass, handgrip strength and usual gait speed according to Asian Working Group on Sarcopenia (AWGS) diagnostic criteria that analyzed by Independent Sample T Test. The sample size with consecutive sampling technique was 149 mens which divided into two groups based on ages of elderly over 60 years $(n=73)$ and young adult between $18-40$ years $(n=76)$. From the independent sample $t$ test results, there was significant difference of muscle mass mean, handgrip strength mean and gait speed mean between elderly group and young adult group by $2.467(\mathrm{SD} \pm 0.1454) \mathrm{kg} / \mathrm{m}^{2}(\mathrm{t}(98.350)=-16.969 ; \mathrm{p}=0.000), 10.455(\mathrm{SD} \pm$ $1.0983) \mathrm{kg}(\mathrm{t}(147)=-9.519 ; \mathrm{p}=0.000)$ and $0.4753(\mathrm{SD} \pm 0.2808) \mathrm{m} / \mathrm{s}(\mathrm{t}(11.636)=-16.747 ; \mathrm{p}=0.000)$ which means along with increasing age, sarcopenia diagnostic components value, i.e. muscle mass, muscle strength, and physical performance will also decrease.
\end{abstract}

Keywords: sarcopenia; bioelectric impedance analysis; handgrip strength; gait speed; AWGS

\section{INTRODUCTION}

Physical ability and performance will decrease along with age, increasing risk of several harmful health problems such as falling, fracture, disability, decreased quality of life, hospitalization and death ${ }^{(1)}$. This condition is characterized by progressive decrease of skeletal muscle mass and function known as sarcopenia ${ }^{(2)}$. Sarcopenia is a condition characterized by loss of muscle mass, muscle strength and muscle function disorder due to aging process ${ }^{(1),(2)}$. It was first mentioned by Irwin Rosenberg in 1989 to explain the loss of muscle mass along with age ${ }^{(3)}$. The newest definition was published by European Working Group of Sarcopenia (EWGSOP) in 2010 whereas inserting changes of muscle function and muscle weakness following decreased muscle mass ${ }^{(2)}$. Sarcopenia can be caused by neurodegenerative process, inadequate nutrition, disuse situation, proinflammatory cytokines such as IL-1, IL-6, and TNF- $\alpha$, and endocrinopathy which causes abnormal thyroid function, increased cortisol, insulin resistance, and decreased anabolic hormone level such as GH, IGF-1, vitamin D and testosterone and estrogen ${ }^{(3)}$. Several studies also found that sarcopenia was more dominant in male compare to female ${ }^{(4),(5),(6)}$.

Currently, the operational definition and diagnostic strategy of sarcopenia in Asia is based on Asian Working Group for Sarcopenia (AWGS) consensus modified from European Working Group on Sarcopenia in Older People (EWGSOP) ${ }^{(7),(8)}$. AWGS recommended the use of two low muscle mass and low muscle function (strength or performance) for the diagnosis of sarcopenia. Diagnosis of sarcopenia according to AWGS and EWGSOP requires the measurement of muscle mass by DXA or bioelectric impedance analysis, muscle strength measurement using handgrip strength and physical performance using usual gait speed test ${ }^{(2),(5),(7),(8)}$. The cut-off value recommended by AWGS was $7.0 \mathrm{~kg} / \mathrm{m}^{2}$ in male and $5.7 \mathrm{~kg} / \mathrm{m}^{2}$ in female for muscle mass measured using bioelectric impedance analysis defined as appendicular skeletal muscle mass $/ \mathrm{height}^{2}, 26 \mathrm{~kg}$ in male and $18 \mathrm{~kg}$ in female for handgrip strength and $0.8 \mathrm{~m} / \mathrm{s}$ for gait speed ${ }^{(7),(8)}$.

EWGSOP divided sarcopenia into three levels, i.e. pre-sarcopenia, sarcopenia and severe sarcopenia ${ }^{(1)}$. Pre-sarcopenia is characterized by decreased muscle mass without any effect on muscle strength or physical 
performance; sarcopenia is characterized by low muscle mass, followed by low muscle strength or physical performance; severe sarcopenia is characterized by the fulfillment of all three definition criteria ${ }^{(1)}$.

This study was conducted to determine the comparison of sarcopenia diagnostic components between two age groups in men and to prove the effect of age on sarcopenia diagnostic components.

\section{METHODS}

This was an analytical observational study with cross-sectional design by measuring muscle mass using bioelectric impedance analysis, muscle strength using handgrip strength and physical performance by measuring usual gait speed using the recommended diagnostic criteria of Asian Working Group for Sarcopenia (AWGS). Sampling technique used was consecutive sampling, whereas samples were collected with specific considerations with the objective of a more representative data ${ }^{(9)}$. The population in this study was the academic community of Faculty of Medicine, Airlangga University and elderlies in Sememi, Putat Jaya, Tambak Rejo, Perak Timur, and Menur community health centers, Surabaya, East Java. This study was conducted from January - July 2019.

The inclusion criteria of samples were male, aged $18-40$ years old or $\geq 60$ years old, able to grip, cooperative, did not use any walker, was not obese or had BMI $<30 \mathrm{~kg} / \mathrm{m}^{2}$ and not an athlete or someone with high exercise intensity (more than three times a week). The variables in this study were age, weight, height, body mass index, appendicular skeletal muscle mass (ASM), muscle mass (ASM/height ${ }^{2}$ ), handgrip strength and usual gait speed. Data analysis used was bivariate analysis using independent sample sample t-test with the help of Software Statistical Product and Service Solution (SPSS) version 25.

Muscle strength was measured using bioelectric impedance analysis (BIA) (Omron HBF-375, Kyoto, Japan). The subjects were asked to stand without shoes on analysis board while gripping detecting instrument with both hands and form $90^{\circ}$ angle with the body. Data for muscle mass was obtained by calculating relative skeletal muscle mass obtained from the calculation of ASM divided by square height in meter ${ }^{(7)}$. Muscle strength assessment was performed using handgrip dynamometer (Camry EH101 Digital Hand Dynamometer, US) in kilograms. The measurement was conducted with three repetitions on both hands and the highest value was obtained while standing ${ }^{(10),(11)}$. Physical performance was measured by measuring gait speed using 4-meter gait speed test ${ }^{(12),(13)}$.

This study had received ethical clearance from Health Research Ethical Committee (KEPK) of Faculty of Medicine, Airlangga University, Surabaya with number 175/EC/KEPK/FKUA/2019.

\section{RESULTS}

This study was conducted in Faculty of Medicine, Airlangga University, Sememi, Putat Jaya, Tambak Rejo, Perak Timur, and Menur community health centers, Surabaya, East Java. The sample size in this study was 149 male volunteers who met inclusion criteria and divided into two age groups, i.e. elderly of more than 60 years old $(n=73)$ and young adults of $18-40$ years old $(n=76)$. The general characteristics of the subjects can be seen in Table 1, with the average age of elderly and young adult groups were $69.01 \pm 6.92$ and $20.36 \pm 0.89$, respectively. The frequency distribution of subjects according to sarcopenia diagnostic components can be seen in Table 2, whereas most subjects had normal handgrip strength, 47 subjects $(64.38 \%)$ were from the elderly and 75 from young adult group. The majority of subjects from young adult group also had normal muscle mass, consisting of 59 subjects $(77.63 \%)$. Meanwhile, the majority of subjects from elderly group had low muscle mass, consisting of 71 subjects $(97.26 \%)$. All subjects from young adult group had normal gait speed, while subjects from elderly group with normal gait speed were 32 people $(43.84 \%)$.

Table 1. Characteristics of study subjects

\begin{tabular}{ccc}
\hline Characteristic & Elderly $(\mathrm{n}=73)$ & Young Adult $(\mathrm{n}=76)$ \\
\hline Age(year), mean \pm SD (range) & $69.01 \pm 6.92(60-86)$ & $20.36 \pm 0.89(18-23)$ \\
Height $(\mathrm{cm})$, mean \pm SD (range) & $158.27 \pm 7.36(135-175)$ & $169.30 \pm 5.43(156-185)$ \\
Weight $(\mathrm{kg})$, mean \pm SD (range) & $55.57 \pm 10.26(35.9-83)$ & $66.30 \pm 10.68(43.9-92.8)$ \\
BMI $\left(\mathrm{kg} / \mathrm{m}^{2}\right)$, mean \pm SD (range) & $22.11 \pm 3.30(15.54-29.2)$ & $23.11 \pm 3.40(16.12-29,86)$ \\
ASM $(\mathrm{kg})$, mean \pm SD (range) & $12.71 \pm 3.92(3.23-27)$ & $20.91 \pm 2.10(16.57-29.17)$ \\
ASM $/ \mathrm{ht}^{2}\left(\mathrm{~kg} / \mathrm{m}^{2}\right)$, mean \pm SD (range) & $4.82 \pm 1.16(1.47-7.6)$ & $7.28 \pm 0.51(6,04-8,71)$ \\
Handgrip strength $(\mathrm{kg})$, mean \pm SD (range) & $28 \pm 6.67(15-44)$ & $38.46 \pm 6.73(24,6-57,4)$ \\
Gait speed $(\mathrm{m} / \mathrm{s})$, mean \pm SD (range) & $0.77 \pm 0.21(0,3-1,32)$ & $1.24 \pm 0.12(1,03-1,65)$ \\
\hline BMI = body mass index; ASM = appendicular skeletal muscle mass; ASM/ht ${ }^{2}=$ appendicular skeletal muscle \\
mass $/$ height $^{2}$.
\end{tabular}

The frequency distribution of subjects according to sarcopenia level can be seen in Table 3, whereas out of 149 subjects, $40(26.85 \%)$ were included in pre-sarcopenia category, 28 (18.79\%) in sarcopenia, $20(27.40 \%)$ 
in severe sarcopenia and $61(40.94 \%)$ in normal category. The majority of the elderly group was included in sarcopenia category with 27 subjects $(36.99 \%)$, while the majority of young adult group was included in normal category with 59 subjects $(77.63 \%)$.

Table 2. Frequency distribution of study subjects according to sarcopenia diagnostic components

\begin{tabular}{ccc}
\hline Variable & \multicolumn{2}{c}{$\mathrm{n}(\%)$} \\
\cline { 2 - 3 } Muscle Mass & Elderly $(\mathrm{n}=73)$ & Young Adult $(\mathrm{n}=76)$ \\
Normal (ASM $\left./ \mathrm{ht}^{2} \geq 7.0 \mathrm{~kg} / \mathrm{m}^{2}\right)^{*}$ & $2(2.74)$ & $59(77.63)$ \\
Low (ASM $\left./ \mathrm{ht}^{2}<7.0 \mathrm{~kg} / \mathrm{m}^{2}\right)^{*}$ & $71(97.26)$ & $17(22.37)$ \\
Handgrip Strength & & $75(98.68)$ \\
Normal $(\geq 26 \mathrm{~kg})^{*}$ & $47(64.38)$ & $1(1.32)$ \\
Low $(<26 \mathrm{~kg})^{*}$ & $26(35.62)$ & $76(100)$ \\
Gait speed & & $0(0)$ \\
Normal $(\geq 0.8 \mathrm{~m} / \mathrm{s})^{*}$ & $32(43.84)$ & $41(56.16)$ \\
Low $(<0.8 \mathrm{~m} / \mathrm{s})^{*}$ & &
\end{tabular}

*according to AWGS recommended sarcopenia diagnostic criteria $^{(7),(8)}$.

Table 3. Frequency distribution of study subjects according to sarcopenia level

\begin{tabular}{cccc}
\hline \multirow{2}{*}{ Sarcopenia Level } & \multicolumn{3}{c}{$\mathrm{n}(\%)$} \\
\cline { 2 - 4 } & Elderly $(\mathrm{n}=73)$ & Young Adult $(\mathrm{n}=76)$ & Total $(\mathrm{n}=149)$ \\
\hline Normal & $2(2.74)$ & $59(77.63)$ & $61(40.94)$ \\
Pre-sarcopenia & $24(32.88)$ & $16(21.05)$ & $40(26.85)$ \\
Sarcopenia & $27(36.99)$ & $1(1.32)$ & $28(18.79)$ \\
Severe sarcopenia & $20(27.40)$ & $0(0.00)$ & $20(13.42)$ \\
\hline
\end{tabular}

\section{Comparison of Muscle Mass Between Two Age Groups}

According to the results of independent sample t-test on muscle mass in Table 4, the significance value was $p<0.05$, which showed that each data group came from different variance of population with $t$-count value $<$ t-table value, thus concluded that there was a significant difference of muscle mass between the elderly $(\mathrm{M}=$ 4.817; $\mathrm{SD}=1.155)$ and young adults $(\mathrm{M}=7.284 ; \mathrm{SD}=0.152)$ of $2.467(\mathrm{SD} \pm 0.1474) \mathrm{kg} / \mathrm{m}^{2}(\mathrm{t}(98.350)=-$ $16.740 ; \mathrm{p}=0.000)$.

Table 4. Results of independent sample t-test on muscle mass between two age groups

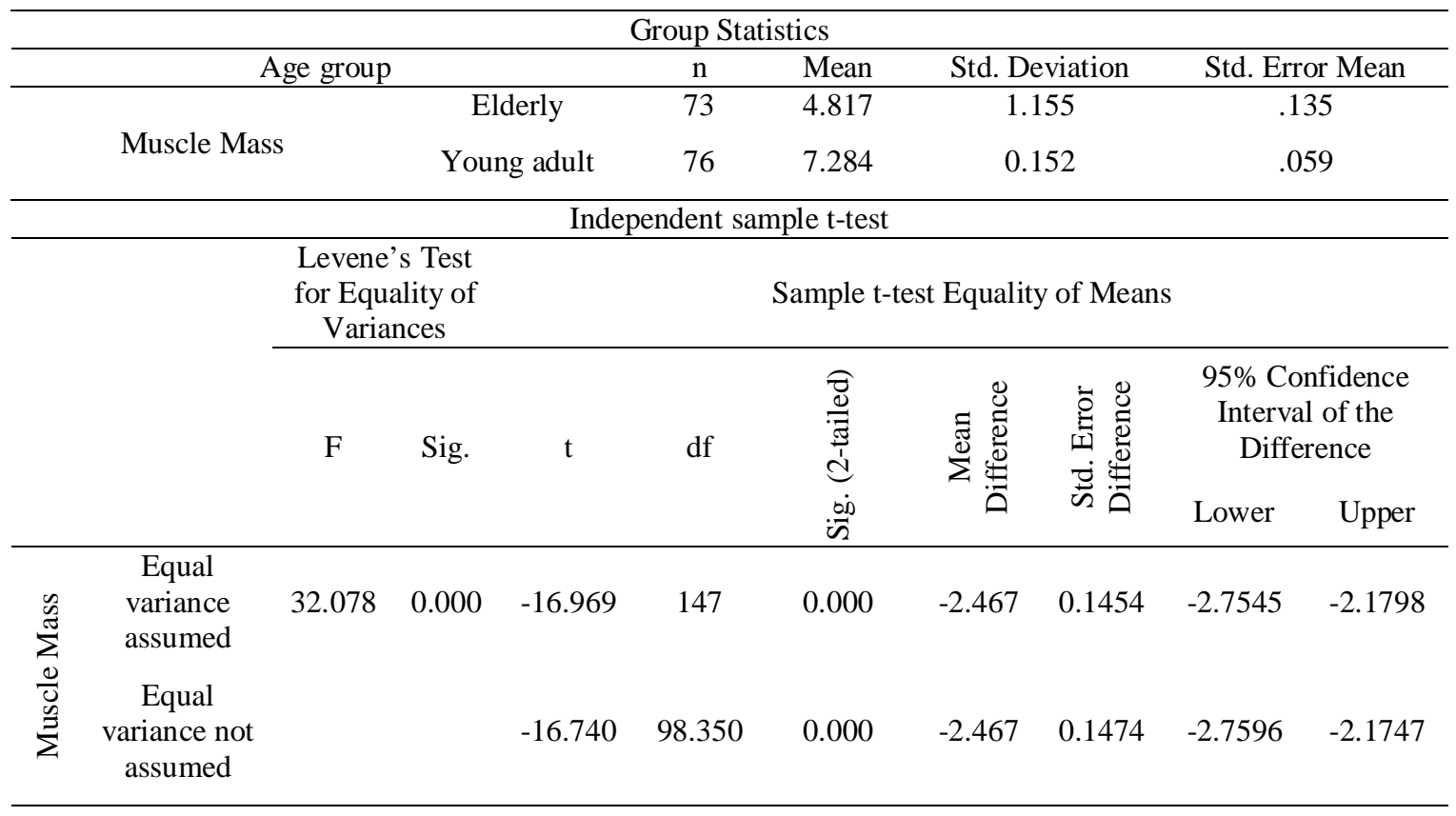




\section{Comparison of Muscle Strength Between Two Age Groups}

According to independent Sample t-test result of handgrip strength in Table 5 found significance value of $\mathrm{p}>0.05$, which showed that each data group were from similar variance of population and obtained t-count value < t-table value, thus there was a significant handgrip strength difference between the elderly $(\mathrm{M}=28 ; \mathrm{SD}$ $=6.675)$ and young adults $(\mathrm{M}=38.455 ; \mathrm{SD}=6.728)$ of $10.455(\mathrm{SD} \pm 1.0983) \mathrm{kg}(\mathrm{t}(147)=-9.519 ; \mathrm{p}=0.000)$.

Table 5. Results of independent Sample t-test on handgrip strength between two age groups

\begin{tabular}{cccccc}
\hline \multicolumn{7}{c}{ Group Statistics } \\
\hline Age Group & \multicolumn{1}{c}{ Mean } & Std. Deviation & Std. Error Mean \\
\hline \multirow{2}{*}{ Handgrip Strength } & Elderly & 73 & 28.000 & 6.675 & 0.781 \\
& Young Adult & 76 & 38.455 & 6.728 & 0.772 \\
\hline \multicolumn{7}{c}{ Independent Sample t-test } \\
\hline
\end{tabular}

Levene's Test

for Equality

of Variances
Sample t-test Equality of Means

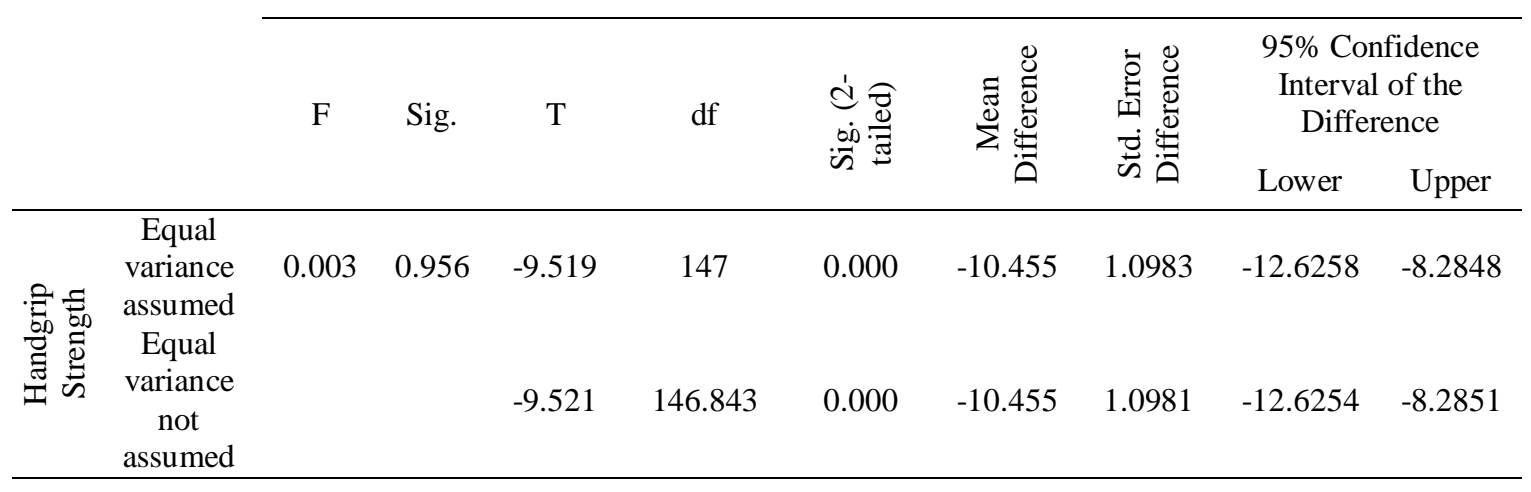

\section{Comparison of Physical Performance Between Two Age Groups}

According to independent Sample t-test results of gait speed in Table 6, the significance value was $\mathrm{p}<$ 0.05 , which showed that the data group were from different variance of population and found t-count value $<\mathrm{t}-$ table value, thus there was a significant gait speed difference between the elderly $(\mathrm{M}=0.768 ; 0.213)$ and young adults $(\mathrm{M}=1.243 ; \mathrm{SD}=0.118)$ of $0.475(\mathrm{SD} \pm 0.0284) \mathrm{m} / \mathrm{s}(\mathrm{t}(11.636)=-16.747 ; \mathrm{p}=0.000)$.

Table 6. Results of independent Sample t-test on gait speed between two age groups

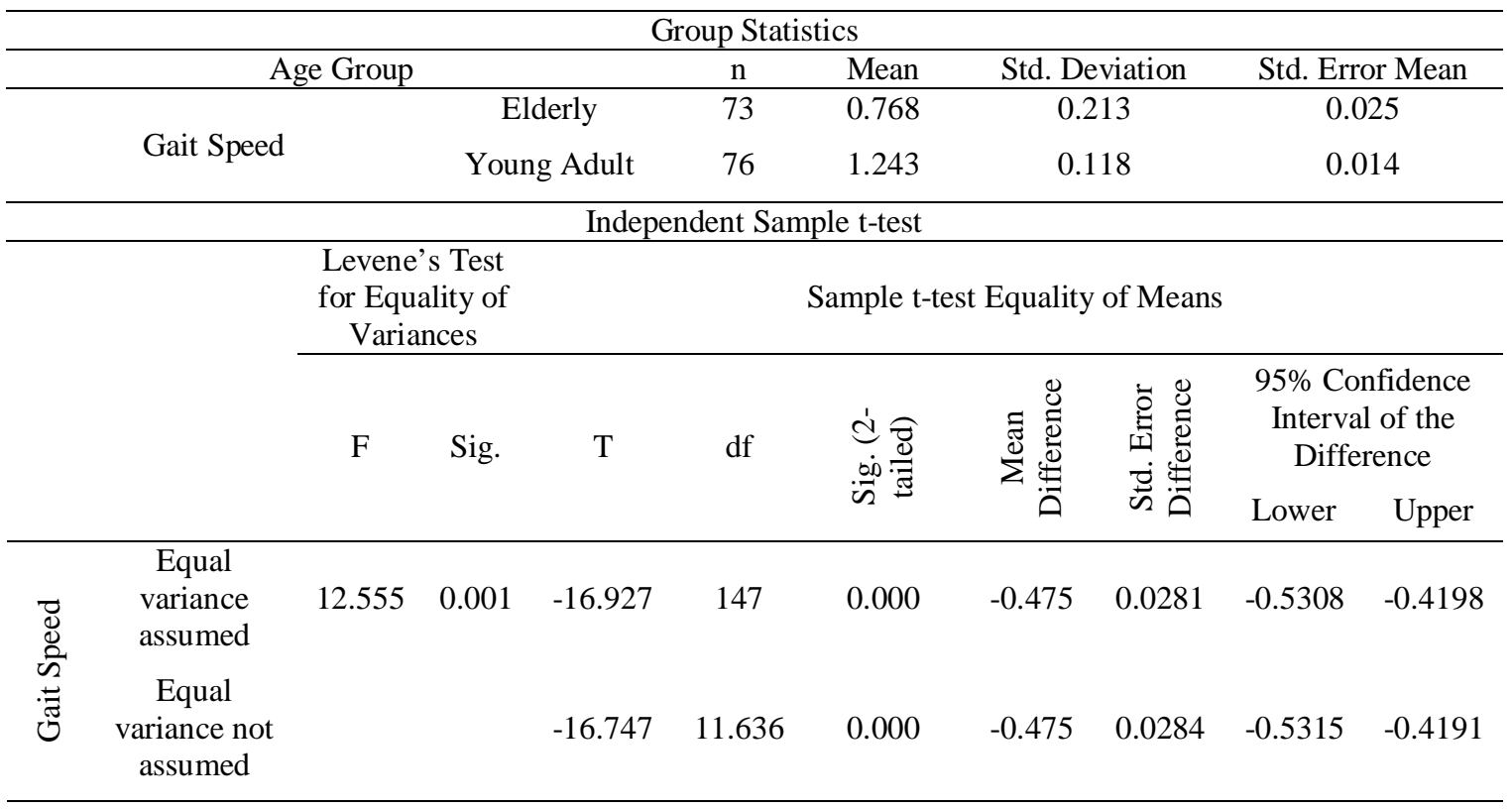




\section{DISCUSSION}

The general characteristics of subjects showed the average age of elderly of $69.01 \pm 6.92$ years which was included in older group according to WHO, while the average age of young adults was $20.36 \pm 0.89$ years, which was included in young adult group according to Lemme ${ }^{(14),(15)}$. It was also found that the young adult group had higher height, weight, BMI, and ASM compared to the elderly group. The result of frequency distribution according sarcopenia diagnostic components revealed that the majority of elderly group had low muscle mass, handgrip strength, and gait speed, in contrast with young adult group who had normal muscle mass, handgrip strength, and gait speed. These was in accordance with a study conducted by Han et al. on 1,609 Chinese population with more than 60 years of age, whereas the majority had low muscle mass, muscle strength and physical performance and increased sarcopenia prevalence in male along with increasing age ${ }^{(6)}$.

The result of frequency distribution of subjects according to sarcopenia level found that out of 149 subjects, 40 of them $(26.85 \%)$ was included in pre-sarcopenia with 24 subjects $(32.88 \%)$ from the elderly group and $16(21.05 \%)$ from young adult group. It was also found that 28 subjects $(18.79 \%)$ from 149 subjects were included in sarcopenia category, with $27(36.99 \%)$ from elderly group and $1(1.32 \%)$ from young adult group. Twenty subjects $(27.40 \%)$ out of 149 subjects were included in severe sarcopenia and all of them were in the elderly group. These results were in accordance with Yazar and Olgun Yazar in Turkey, whereas the prevalence of severe sarcopenia increased along with increasing age in male and female, and the prevalence of sarcopenia increased along with increasing decades in female from 70 years and male form 50 years and found prevalence of pre-sarcopenia in subjects under 50 years old and more than $25 \%$ participants were aged more than 80 years old were included in severe sarcopenia and the prevalence of sarcopenia (pre-sarcopenia, sarcopenia, and severe sarcopenia) in male subjects above 80 years old were $48.3 \%$ higher than female ${ }^{(16)}$.

The results of independent Sample t-test revealed significant differences of muscle mass, handgrip strength and gait speed between elderly group and young adult group, each difference being 2.467 (SD \pm $0.1474) \mathrm{kg} / \mathrm{m}^{2}(\mathrm{t}(98.350)=-16.740 ; \mathrm{p}=0.000), 10.455(\mathrm{SD} \pm 1.0983) \mathrm{kg}(\mathrm{t}(147)=-9.519 ; \mathrm{p}=0.000)$ and 0.475 $(\mathrm{SD} \pm 0.0284) \mathrm{m} / \mathrm{s}(\mathrm{t}(11.636)=-16.747 ; \mathrm{p}=0.000)$, respectively. Around the fourth decade, muscle mass started to decrease and accelerated with increasing age ${ }^{(17)}$. After 35 years old, physiological decrease of $1-2 \%$ muscle mass occurs each year and $1.5 \%$ decrease of muscle strength per year, accelerated by $3 \%$ after 60 years of age $^{(18)}$. Low muscle mass and muscle strength directly related to BMI, thus low BMI can cause low muscle mass and handgrip strength that may be caused by low calorie intake ${ }^{(19)}$. A study in Korea explained that total energy intake is a highly significant factor in sarcopenia in adults ranging from 20-39 years old ${ }^{(20)}$. High BMI had protective effect on sarcopenia and this study found several subjects had BMI under $21 \mathrm{~kg} / \mathrm{m}^{2}$, whereas according to Kim et al., BMI under $21 \mathrm{~kg} / \mathrm{m}^{2}$ predicted muscle mass decrease ${ }^{(19),(21)}$. Decrease of three sarcopenia diagnostic components can be caused by decreased anabolic hormonal level such as testosterone, which is the main anabolic hormone which can increase protein synthesis in skeletal muscles through satellite cell activities $^{(22)}$. Decreased testosterone serum level of $1 \%$ per year in healthy male aged 30-40 years old seems related to decreased muscle mass, muscle strength and physical performance affected by both ${ }^{(23),(24)}$.

The results of this test were in line with a study in Europe with 515 volunteers divided into several age groups, i.e. 18-39 years, 40-49 years, 50-59 years, 60-69 years, 70-79 years and 80 years and above, whereas significant decrease was found on muscle mass, handgrip strength, and gait speed in line with increasing age, whereas decreased handgrip strength and gait speed started after 50 years of age and decreased SMMI value started from 70 years of age in male ${ }^{(16)}$. The results of this study was also in line with a study in Turkey on 301 participants ranging from 18-39 years old, whereas 187 of them were male with $26.8 \pm 4.5$ years of age and 406 elderlies which consisted of 123 males with average age of $77.5 \pm 6.2$ years and each had average SMI or muscle mass of $11 \pm 0.9 \mathrm{~kg} / \mathrm{m}^{2}$ and $10.8 \pm 1.1 \mathrm{~kg} / \mathrm{m}^{2}$, handgrip strength $53.4 \pm 7.2 \mathrm{~kg}$ and $34.5 \pm 8.4 \mathrm{~kg}$ and gait speed $1.4 \pm 0.2 \mathrm{~m} / \mathrm{s}$ and $0.95 \pm 0.3 \mathrm{~m} / \mathrm{s}$, respectively ${ }^{(25)}$.

The limitations of this study include undiscussed comorbidity effect of all subjects on sarcopenia components and the subjects had not represented all age groups, only two age groups, i.e. 18-40 years and more than 60 years.

\section{CONCLUSION}

Along with increasing age, sarcopenia diagnostic components value, i.e. muscle mass, muscle strength, and physical performance will also decrease. There were significant mean differences on muscle mass, handgrip strength, and gait speed between elderly group and young adult group. 


\section{REFERENCES}

1. Cruz-Jentoft A, Baeyens J, Bauer J, Boirie Y, Cederholm T, Landi F et al. Sarcopenia: European consensus on definition and diagnosis: Report of the European Working Group on Sarcopenia in Older People. Age and Ageing. 2010;39(4):412-423.

2. Vitale G, Salvioli S, Franceschi C. Oxidative stress and the ageing endocrine system. Nature Reviews Endocrinology. 2013;9(4):228-240.

3. Rosenberg I. Sarcopenia: Origins and Clinical Relevance. The Journal of Nutrition. 1997;127(5):990S-991S.

4. Morley J, Anker S, von Haehling S. Prevalence, incidence, and clinical impact of sarcopenia: facts, numbers, and epidemiology-update 2014. Journal of Cachexia, Sarcopenia and Muscle. 2014;5(4):253-259.

5. Landi F, Calvani R, Cesari M, Tosato M, Martone A, Bernabei R et al. Sarcopenia as the Biological Substrate of Physical Frailty. Clinics in Geriatric Medicine. 2015;31(3):367-374.

6. Han P, Kang L, Guo Q, Wang J, Zhang W, Shen S et al. Prevalence and Factors Associated with Sarcopenia in Suburb-dwelling Older Chinese Using the Asian Working Group for Sarcopenia Definition. The Journals of Gerontology Series A: Biological Sciences and Medical Sciences. 2015;71(4):529-535.

7. Limpawattana P, Kotruchin P, Pongchaiyakul C. Sarcopenia in Asia. Osteoporosis and Sarcopenia. 2015;1(2):92-97.

8. Chen L, Liu L, Woo J, Assantachai P, Auyeung T, Bahyah K et al. Sarcopenia in Asia: Consensus Report of the Asian Working Group for Sarcopenia. Journal of the American Medical Directors Association. 2014;15(2):95-101.

9. Sugiyono. Metode Penelitian Pendidikan Pendekatan Kuantitatif, kualitatif, dan R\&D. Bandung: Alfabeta; 2010. p. 218

10. Liu L, Lee W, Liu C, Chen L, Lin M, Peng L et al. Age-related skeletal muscle mass loss and physical performance in Taiwan: Implications to diagnostic strategy of sarcopenia in Asia. Geriatrics \& Gerontology International. 2013;13(4):964-971.

11. Barbat-Artigas S, Pinheiro Carvalho L, Rolland Y, Vellas B, Aubertin-Leheudre M. Muscle Strength and Body Weight Mediate the Relationship Between Physical Activity and Usual Gait Speed. Journal of the American Medical Directors Association. 2016;17(11):1031-1036.

12. Maggio M, Ceda G, Ticinesi A, De Vita F, Gelmini G, Costantino C et al. Instrumental and NonInstrumental Evaluation of 4-Meter Walking Speed in Older Individuals. PLOS ON10E. 2016;11(4):e0153583.

13. Gunasekaran V, Banerjee J, Dwivedi S, Upadhyay A, Chatterjee P, Dey A. Normal gait speed, grip strength and thirty seconds chair stand test among older Indians. Archives of Gerontology and Geriatrics. 2016;67:171-178.

14. World Health Organization. Men, ageing and health: achieving health across the lifespan [Internet]. Geneva: World Health Organization; 2001 [cited 11 October 2019]. Available from: https://apps.who.int/iris/handle/10665/66941

15. Lemme B. Development in adulthood. 4th ed. Boston: Pearson; 2010.

16. Yazar T, Olgun Yazar H. Prevalance of sarcopenia according to decade. Clinical Nutrition ESPEN. 2019;29:137-141.

17. Peterson C, Johannsen D, Ravussin E. Skeletal Muscle Mitochondria and Aging: A Review. Journal of Aging Research. 2012;2012:1-20.

18. Frontera W, Hughes V, Fielding R, Fiatarone M, Evans W, Roubenoff R. Aging of skeletal muscle: a 12-yr longitudinal study. Journal of Applied Physiology. 2000;88(4):1321-1326.

19. Kim H, Suzuki T, Kim M, Kojima N, Yoshida Y, Hirano H et al. Incidence and Predictors of Sarcopenia Onset in Community-Dwelling Elderly Japanese Women: 4-Year Follow-Up Study. Journal of the American Medical Directors Association. 2015;16(1):85.e1-85.e8.

20. Bae E, Kim Y. Factors Affecting Sarcopenia in Korean Adults by Age Groups. Osong Public Health and Research Perspectives. 2017;8(3):169-178.

21. Landi F, Liperoti R, Fusco D, Mastropaolo S, Quattrociocchi D, Proia A et al. Prevalence and Risk Factors of Sarcopenia Among Nursing Home Older Residents. The Journals of Gerontology Series A: Biological Sciences and Medical Sciences. 2011;67A(1):48-55.

22. La Colla A, Pronsato L, Milanesi L, Vasconsuelo A. 17ß-Estradiol and testosterone in sarcopenia: Role of satellite cells. Ageing Research Reviews. 2015;24:166-177.

23. Feldman H. Age Trends in the Level of Serum Testosterone and Other Hormones in Middle-Aged Men: Longitudinal Results from the Massachusetts Male Aging Study. Journal of Clinical Endocrinology \& Metabolism. 2002;87(2):589-598.

24. Perkisas S, De Cock A, Verhoeven V, Vandewoude M. Physiological and architectural changes in the ageing muscle and their relation to strength and function in sarcopenia. European Geriatric Medicine. 2016; 7(3):201-206. 
25. Bahat G, Tufan A, Tufan F, Kilic C, Akpinar T, Kose M et al. Cut-off points to identify sarcopenia according to European Working Group on Sarcopenia in Older People (EWGSOP) definition. Clinical Nutrition. 2016;35(6):1557-1563. 